\title{
An Overview on Total Analytical Methods for the Detection of 1,4-Benzodiazepines
}

\author{
Mohammad Nasir Uddin ${ }^{1 *}$, Victoria F, Samanidou² and loannis N Papadoyannis ${ }^{2}$ \\ ${ }^{1}$ Department of Chemistry, University of Chittagong, Chittagong, Bangladesh \\ ${ }^{2}$ Laboratory of Analytical Chemistry, Department of Chemistry, Aristotle University of Thessaloniki, Thessaloniki, Greece
}

\begin{abstract}
Considering the high consumption of benzodiazepines worldwide, there is increased potential for addiction and abuse in cases of crime, driving under the influence of drugs, suicide and drug-facilitated sexual assault (DFSA). For these reasons, this class of drugs and their metabolites are frequently present in both clinical and forensic cases. Therefore, it is important to develop an efficient sample preparation procedure as well as method able to determine benzodiazepines in different matrices. In this article the information concerning the current available analytical methods for the determination of 1,4-benzodiazepines (BDZs) in biological materials and pharmaceutical formulations are reviewed. Developed methods are classified as chromatography (HPLC, TLC, GC, MLC), capillary electro-chromatography, capillary electrophoresis, immunoassays, Photometric (spectrophotometric, spectrofluorometric) and electroanalytical (potentiometric, polarographic, voltammetry). These methods have been extensively applied to the analysis of number of benzodiazepine derivative drugs providing reliable and accurate results. Moreover, the analytical methods related to these studies are also described and commented upon and their most important characteristics are highlighted. Therefore sample pretreatment including protein removal followed by extraction should be mandatory for the isolation of benzodiazepines (BDZs) from complex bio-matrices. In this regarding modern isolation techniques e.g. SFE, MISPE, ASPEC, DLLME have been reviewed.
\end{abstract}

Keywords: Benzodiazepines; Gamma-aminobutyric acid

\section{Introduction}

Benzodiazepines (BDZs) are the chemicals having the versatile medicinal values. These are the type of psychotropic drug, that is, they concern the mind and can amend frame of mind. Benzodiazepines enhance the effect of the neurotransmitter gamma-aminobutyric acid (GABA) and are subsequently used therapeutically as anxiolytics, tranquilizers, hypnotics, anticonvulsants in epilepsy and centrally acting muscle relaxants. Benzodiazepines (BDZs) are generally commonly used as anxiolytic and/or hypnotic drugs as a ligand of the GABA-benzodiazepine receptor. Moreover, some of benzodiazepines are widely used as an anti-depressive and sedative drugs, and also as anti-epileptic drugs and in some cases can be useful as an adjunct treatment in refractory epilepsies or anti-alcoholic therapy. The widespread use of this class of drugs has occasionally raised concern about recreational benzodiazepine abuse and has led to the erroneous impression that benzodiazepines have a relatively high abuse liability among recreational drug users. The abuse or misuse of benzodiazepines is internationally widespread which means that any forensic laboratory may encounter a range of these compounds. In general, benzodiazepines encountered in the illicit market are diverted from legitimated sources. Benzodiazepine derivatives are prescribed in large quantities globally and are potentially new emerging environmental contaminants [1]. Analysts should be aware of the particular benzodiazepines commonly available in their area as well as the characteristics and methodologies for their identification and analysis. Because of the high consumption of benzodiazepines worldwide, this class of drugs and their metabolites are frequently present in both clinical and forensic cases. For these reasons, the analysis of benzodiazepines and their metabolites in biological fluids is of great interest to clinicians and forensic toxicologists.

In recent years a large number of analytical and pharmacological studies on 1,4-benzodiazepines and their metabolites in biological samples have been described. The dominant assay methods include liquid chromatography (LC/HPLC) [2], gas chromatography (GC)
[3], micellar liquid chromatography (MLC) [4], micellar electrokinetic chromatography (MEKC) [5], potentiometry [6], spectrophotometry [7], fluorimetry [8], capillary electrophoresis [9] and immunoassay [10]. Procedures for quantification of drugs reviewed by different authors [11-13] included benzodiazepines in the bio-samples blood, plasma, serum, or oral fluid (saliva, etc.) using liquid chromatography coupled with single-stage or tandem mass spectrometry (LC-MS, LCMS-MS) [14]. Literature devoted to drug testing in hair by HPLC/GC [15] has been reviewed. The application of capillary electrophoresis to the detection and determination of 1,4-benzodiazepine tranquilizers in formulations and body materials has been critical evaluated [16]. A review addressed the use of high-performance liquid chromatography (HPLC) and capillary electrophoresis (CE) as affinity separation methods to characterize drugs or potential drugs-biopolymer interactions [17]. Another one deals with the different methods of analysis of certain tranquilizers; phenothiazines, thioxanthenes, and benzodiazepine derivatives in biological fluids of pharmaceutical interest [18]. Only one elaborate report covered chromatographic methods, HPLC, LC-MS, GC, GC-MS published over the years 1992 to 1997 for the measurement of benzodiazepines in biological samples, which included samples preparation partially [19]. Authors reviewed different aspects of HPLC [20] and GC [21] chromatographic methods in previously published articles. Brief discussion on HPLC and GC chromatographic methods has been included herein. This review

*Corresponding author: Mohammad Nasir Uddin, Department of Chemistry, University of Chittagong, Chittagong, Bangladesh, Tel: 0088-01710915011; E-mail: nasircu72@gmail.com, mnuchem@cu.ac.bd

Received May 23, 2014; Accepted June 26, 2014; Published June 30, 2014

Citation: Uddin MN, Samanidou VF, Papadoyannis IN (2014) An Overview on Total Analytical Methods for the Detection of 1,4-Benzodiazepines. Pharm Anal Acta 5: 303. doi:10.4172/2153-2435.1000303

Copyright: ( 2014 Uddin MN, et al. This is an open-access article distributed under the terms of the Creative Commons Attribution License, which permits unrestricted use, distribution, and reproduction in any medium, provided the original author and source are credited. 
included all possible analytical methods devoted for the determination of benzodiazepines in pharmaceutical formulations and biological samples. Figure 1 shows the comparison on the total paper published for the benzodiazepine analysis by the period of 2006-2013.

\section{Data collection}

For the collection of references websites e. g. Since direct, Pubmed, Springerlink, Google were searched several times by the period of March and May, 2014 and articles published within study period was collected.

\section{Properties and physiological action}

Numerous benzodiazepines have reportedly been synthesized and over fifty of these are marketed for clinical use throughout the world. The classical benzodiazepines are based on a 5-aryl-1,4-benzodiazepine structure (Figure 2). The seven- membered amino-ring was essential for its affinity towards the BDZs-binding site and the molecular lipophilic properties of numerous BDZs played a significant role in their corresponding receptor affinity.

Benzodiazepines are weak basic drugs and as free bases are lipidsoluble and water-insoluble. Stock solutions of 1, 4-benzodiazepines in methanol, ethanol or acetonitrile are stable for 3-6 months, when they were kept at $-4^{\circ} \mathrm{C}$ in the dark. Benzodiazepines are stable in biological media when stored at $-20^{\circ} \mathrm{C}$ for several weeks or months [22]. Studies showed that some of benzodiazepines are photolabile, and the photoinstability of alprazolam increases as the $\mathrm{pH}$ decreases.

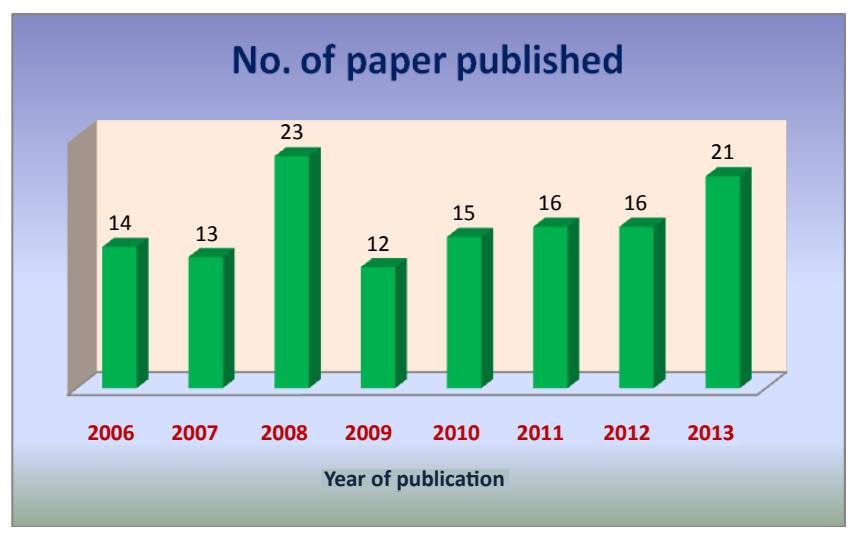

Figure 1: Comparison on the publications by the period of 2006-2013.

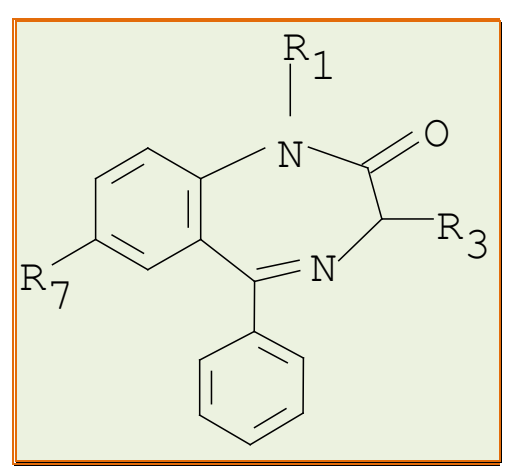

Figure 2: Basic 5-phenyl-1,4-benzodiazepine skeleton.

Where, $\mathrm{R}_{1}=\mathrm{H}, \mathrm{CH}_{3}, \mathrm{R}_{3}=\mathrm{H}$, OH or $\mathrm{COOH}, \mathrm{R}_{5}=\mathrm{Ph}$, and $\mathrm{R}_{7}=\mathrm{NO}_{2}, \mathrm{Cl}$.
Lorazepam was shown to be quickly photodegradated by direct solar radiation, with a half-life time lower than one summer sunny day. On the contrary, oxazepam, diazepam and alprazolam showed to be highly resistant to photodegradation with half-life times of 4, 7 and 228 summer sunny days, respectively [23].

Other nitrogen atoms, as in the 7-amino derivatives, can also be protonated. The hydroxyl group in the 3-hydroxy derivatives can be deprotonated at high $\mathrm{pH}$ values, whilst the $\mathrm{N}$-oxide group in 4 - $\mathrm{N}$-oxidederivatives is protonated at low $\mathrm{pH}$ values. Major metabolic pathway of 1,4-benzodiazepines involves hepatic hydroxylation via cytochrome P450 thus forming hydroxy- metabolites. Recently, flubromazepam (7-bromo-5-(2-fluorophenyl)-1,3-dihydro-2H-1,4-benzodiazepin2-one), a second designer benzodiazepine, was offered. It appears to have an extremely long elimination half-life of more than $100 \mathrm{~h}$. One monohydroxylated compound and the debrominated compound could be identified as the predominant metabolites [24].

Thesedrugsdiffer in their pharmacokineticand metabolic properties. In particular, they are biotransformed by different cytochrome $\mathrm{P} 450$ isoforms and also by different UDP-glucuronosyltransferase subtypes. The most important studies on the metabolic characteristics of several 1,4-benzodiazepines, carried out from 1998 onwards, are reported and briefly discussed [25]. Benzodiazepines bind with specific receptors in the nervous system that are the part of GABA neurotransmitter system. GABA (gamma-amino-butyric acid) is the major neurotransmitter for the maintenance of chloride channel which controls the anxiolytic activity. GABA receptor, imaginatively called the benzodiazepine site, which is different from the GABA binding site. Binding of benzodiazepine derivatives to that particular site, enhance the effect of GABA to shut down brain activity more effectively.

\section{Bio-sample preparation and isolation of benzodiazepines}

Whole blood, serum, plasma, urine, saliva, liver tissues are the biological samples usually analyzed for benzodiazepines. Samples collected in a tube containing an anticoagulant (e.g. heparin, EDTA, citrate or oxalate) can be kept for $6 \mathrm{~h}$ at room temperature, or for 1-2 days at $4^{\circ} \mathrm{C}$. For longer storage period samples should be frozen at $-20^{\circ} \mathrm{C}$. Urine samples must be stored by freezing at $-20^{\circ} \mathrm{C}$ or by the addition of a preservative agent such as toluene, boric acid or concentrated hydrochloric acid. 1,4-Benzodiazepines are usually present at trace levels $\left(\mu \mathrm{gL}^{-1}\right.$ or $\left.\mathrm{ng} \mathrm{mL}^{-1}\right)$ in a complex biological matrix and the potentially interfering compounds need to be removed before analysis. Therefore sample pretreatment including protein removal followed by extraction should be capable of concentrating the sample and reducing the amount of interfering substances. In most cases, a single extraction or pre-concentration procedure is enough to reduce the sample complexity or to improve the LODs of the methods. Blood, plasma and serum are often being deproteinized and hair needs incubation, while urine may require hydrolysis prior to the isolation procedure. Extraction of hair was performed by overnight incubation in a mixture of methanol:acetonitrile:formiate buffer pH 3 (10:10:80) [26]. Hair samples were extracted with a mixture of water: acetonitrile: $1 \mathrm{M}$ trifluoroacetic acid (80:10:10, v/v) using a 5 min simultaneous pulverization/extraction step [27]. Saliva needs no deproteination as it contains protein negligible. Enzymatic digestion [hydrolysis] [28] of plasma, urine, hair, tissue samples of benzodiazepines before extraction to liberate the conjugated fraction of the drug is recommended. $\beta$-Glucuronidase or Gluculase $[\beta$-Glucuronidase + Sulphatase] has been used to release benzodiazepines from any type of conjugate. Usually plasma or serum protein precipitation consists of mixing one volume of plasma or serum with three volumes of acid 
or organic solvent followed by vortex-mixing and centrifugation, which releases the 1,4-benzodiazepines from protein-binding sites removing $99 \%$ of the proteins. The addition of sodium octylsulphate or sodium dodecylsulphate that disrupt the structure of proteins is an alternative way to release 1,4-benzodiazepines from proteins without precipitation. Other methods such as ultramicro-filtration and equilibrium dialysis remove proteins from blood samples. Hair samples are washed before incubation preferably with dichloromethane or $0.1 \%$ sodium dodecylsulfate. Mixture of $\beta$-glucuronidase and arylsulfatase at $\mathrm{pH} 4$, or $8 \mathrm{M}$ urea- $0.2 \mathrm{M}$ thioglycolate solution at $\mathrm{pH} 3$ are reported for hair incubation. An overview included elaborated sample preparation and isolation technologies for the chromatographic determination of 1,4-benzodiazepines in biological matrices [29]. Dried blood spots (DBS) sampling has gained popularity in the bioanalytical community as an alternative to conventional plasma sampling, as it provides numerous benefits in terms of sample collection and logistics. DBS analysis is simple lowering the costs and environmental impact [30].

\section{Extraction techniques}

The sample pre-concentration step typically consists of the extraction of the components of interest from biological matrices. Recent research activities are being focused on the development of efficient, economical, and miniaturized sample preparation methods. Consequently, following distinct type procedures have been used extensively.

1. Liquid-liquid extraction (LLE)

2. Supercritical fluid extraction (SFE)

3. Solid-phase extraction (SPE)

4. Molecularly imprinted solid-phase extraction (MISPE)

5. On-line solid-phase extraction, ASPEC (Automated Sample Preparation with Extraction Columns) System, Column Switching.

6. Micro-extraction (SPME, LPME)

7. Dispersive liquid-liquid micro-extraction (DLLME)

8. Non-extraction procedures (Dialysis of bio-fluids using a semipermeable membrane or direct injection of crude samples after protein precipitation)

As Figure 3 reflects conventional LLE [31,32], (ethyl acetate [33], $0.2 \%$ formic acid [34] etc.) or SPE [35-38] are still widely used by most

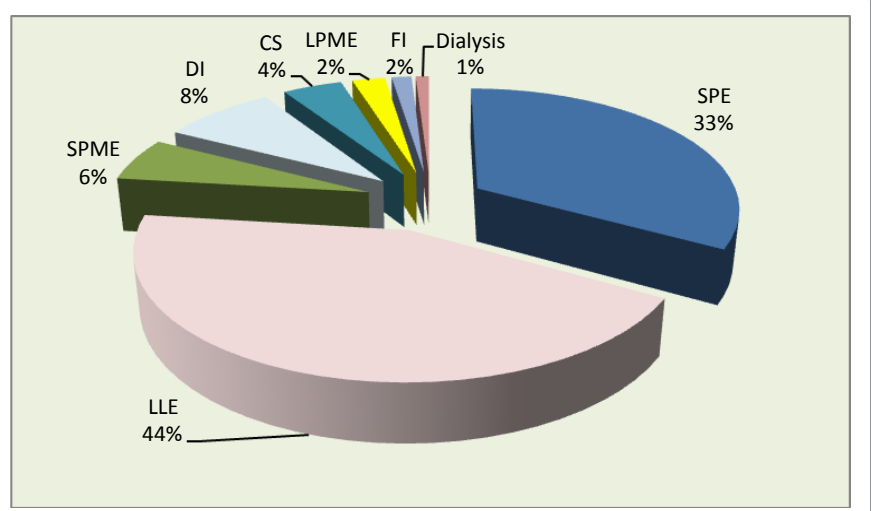

Figure 3: A comparision on the extraction techniques applied to the benzodiazepine estimation. researchers as isolation steps with no obvious relative advantages. Methanol extraction procedure for benzodiazepines determination is useful for forensic toxicological purposes and in case of a small amount of hair available a phosphate extraction is preferred [39]. Both liquidliquid-extraction (LLE) and solid-phase-extraction (SPE) are employed in the blood, oral fluid sample pre-treatment before GC-MS analysis [40]. Midazolam was extracted from the plasma using a three-step liquid-liquid extraction including extraction with an isopropanol/ butyl chloride mixture in an alkaline solution, followed by extractions with $1 \mathrm{M} \mathrm{HCl}$, and finally with an alkaline solution of butyl chloride [41]. SPME and LPME offer relatively new approaches to sample preparation. These require fewer organic solvents, which is important from an ecological and analytical viewpoint. A thin-film octadecyl (C18)-silica glass coating was developed as the extraction phase for an automated 96-blade solid-phase microextraction (SPME) system for the analysis of benzodiazepines in human plasma [42]. They are also fast, solvent-free and provide excellent performances. Hollow fiber liquid phase microextraction (HF-LPME) method based on supramolecular solvents was proved to be efficient and environmental friendly extraction benzodiazepine drugs [43]. Fully automated solid-phase extraction [44] is presented for benzodiazepines in whole blood. The automated sample preparation setup also minimized human exposure to hazardous materials, provided highly improved ergonomics, and eliminated manual pipetting. Cloud point extraction (CPE) technique were developed and optimized for the extraction and preconcentration of oxazepam from human urine [45].

A mixed-mode cation-exchange polymeric sorbent $[37,46,47]$ was used for solid phase extraction of benzodiazepines in human whole blood. Benzodiazepines can be extracted from biological fluids, such as blood and urine using QuEChERS ("catchers") [48], a novel sample preparation technique used for high aqueous content samples. Benzodiazepines in whole blood at pH 11 (borate buffer) were extracted by solid-supported liquid-liquid extraction on ChemElut $\left({ }^{\circ}\right)$ columns using methyl tert-butyl ether. Dispersive liquid-liquid micro-extraction (DLLME) [49] technique was successfully used as a sample preparation method for the determination of clonazepam in pharmaceutical preparations and water samples. SPE combined with dispersive liquid-liquid microextration [50] was used for the extraction of ultra-trace amounts of benzodiazepines (BZPs) including, diazepam, midazolam, and alprazolam, from ultra-pure water, tap water, fruit juices, and urine samples. Efficient ultrasound-assisted dispersive liquid-liquid microextraction (UA-DLLME) [51] method has been developed for the determination of seven benzodiazepines in human plasma samples. In this method, a suitable mixture of methanol (disperser solvent) and chloroform (extraction solvent) was injected rapidly into a conical test tube that contained an aqueous solution of benzodiazepines. After centrifuging, phase separation was performed by sedimenting the fine droplets of the micro-extraction solvent on the bottom of a test tube (about $100 \mu \mathrm{L}$ ) and then the absorbance of the enriched extracted phase was determined at the absorption wavelength. Results show that dispersive liquid-liquid microextraction combined with HPLC-UV is a fast and simple method for the determination of chlordiazepoxide in water, urine, plasma, and tablet samples [33,52]. Parameters of microwave-assisted extraction (type of extraction solvent, extraction temperature, extraction time and $\mathrm{pH}$ of borate buffer) were optimized and validated for isolation of benzodiazepine in hair. Limit of detection of $0.003-0.025 \mathrm{ng} / \mathrm{mg}$ was achieved for UHPLC-MS-TOF analysis of clinical hair sample [53]. Molecularly imprinted microspheres (MIMs) for the drug diazepam and its main 
metabolite (nordiazepam) were prepared and used to separate the two species from urine and serum samples [54].

\section{Classification of Analytical Methods}

Analytical methods used for benzodiazepines analysis are broadly categorized as the following-

- Chromatography [LC (HPLC, UPLC, MLC, Chiral separation), GC, and TLC],

- Capillary electro-separation (MEKC, CEC, capillary electrophoresis),

- Immunoassay,

- Photometry (UV-spectrometry, FTIR),

- Electro-analytical (potentiometric, voltammetric and polarographic)

Different methods applied for benzodiazepines analysis are graphically presented in Figure 4.

\section{Chromatographic methods}

In the context of this review emphasize has been given to TLC, micellar liquid chromatography (MLC) and micellar (electrokinetic) capillary chromatography (MECC). Elaborate discussion on chiral liquid chromatography (Chiral LC) has been attempted rather than HPLC, GC procedure as later two methods are individually reviewed. Chromatographic methods can either be used to screen biological samples for the presence of one or more benzodiazepines, or confirm the presence of one or more benzodiazepines following an initial immunoassay or other screening test.

High performance liquid chromatography (HPLC): There was no obvious preference for choice of column, except for reversed-phase $\mathrm{C}_{18}$ [55] or $\mathrm{C}_{8}$, [56] which was more prevalent than the alternative phases. Monolithic columns [57], consisting of continuous beds with through pores of organic or inorganic matrix, have found increasing applications for HPLC separations. However, other packing materials, addition of organic modifiers or other chromatographic mechanisms could be considered for reducing peak tailing. A new HPLC polymer stationary phase, MSpak GF column [20], consisting of a highly crosslinked hard gel of polyvinyl alcohol, established rapid and simple chromatographic methods for analyzing benzodiazepines by direct injection of samples (plasma, urine) without the extraction procedure or without the column-switching technique. DAD detection provides

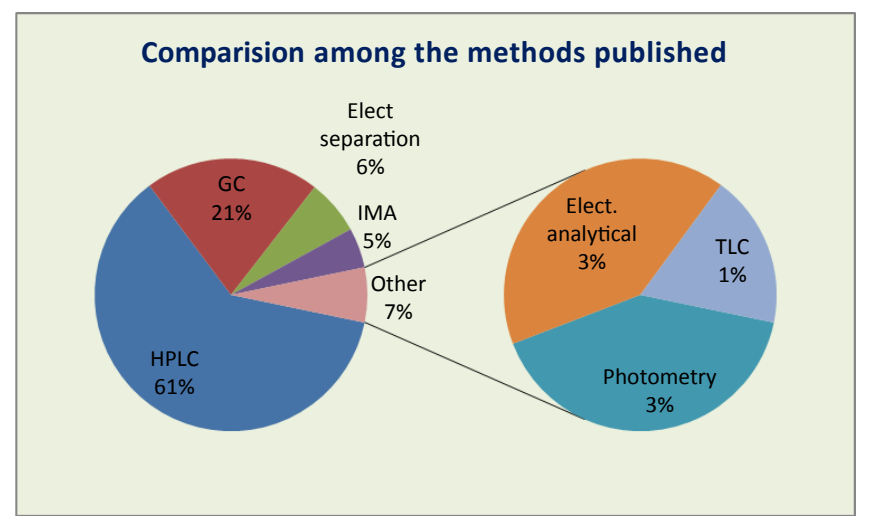

Figure 4: Comparison on different methods applied for the estimation of benzodiazepines. an improved means to exclude co-eluting substances [55,58]. Some promising results have been obtained by using electrochemical detectors, but further work is required to see how these detectors compare with the well-established ultraviolet detectors, in terms of overall performance. In particular, the combination of HPLC with MS appears to offer an important alternative to conventional GC-MS for the identification new metabolites of the drugs. With the introduction of more sensitive detectors (maximum sensitivity 0.001 AUFS), novel column systems and automation of the equipment, the use of HPLC in benzodiazepine analysis is likely to increase. In fine HPLC, a method of increasing importance for these purposes is being used with ultraviolet, fluorescence or electrochemical detection and even with MS applying soft ionization interfaces like thermospray ionization (TSP), electrospray ionization (ESI), sonic spray ionization (SSI), atmospheric pressure chemical ionization (APCI) or photoionization (APPI). The application of HPLC-MS-MS for qualitative and quantitative analysis of benzodiazepines has been described more recently [38,59-61]. MS modes; electrospray ionization (ESI), multiple reaction monitoring (MRM), information dependent acquisition (IDA), enhanced product ion scan (EPI) were compared [62] for detection and quantification of 21 benzodiazepines in human hair samples. Electrospray ionization was found to be more efficient than atmospheric pressure chemical ionization. The use of a mobile phase of high $\mathrm{pH}$ resulted in higher retention and higher electrospray ionization signals than the conventional low $\mathrm{pH}$ mobile phases. Considering the benefits of a high $\mathrm{pH}$ mobile phase on both chromatography and mass spectrometry, its use should be encouraged [47]. The reason for using tandem mass spectrometry is to increase limits of detection without the need for chemical derivatization [63]. Online extraction LC-MS/MS method has been developed for the simultaneous quantitative confirmation of benzodiazepines and metabolites in urine $[28,64]$ and in hair [65]. A comparison shows that the corresponding LOD and LOQ values are approximately three orders of magnitude lower in HPLC than in CZE [66]. Ultra-performance liquid chromatography-tandem mass spectrometry (UPLC-MS/MS or TOF-MS) assay method was developed and validated for simultaneous determination of benzodiazepines in human urine [34,67], serum [68], plasma [31] whole blood [69,70], hair [26].

Chiral liquid chromatography (HPLC) is a well-established area of bioanalytical chemistry and is often used during the processes of drug discovery and development. Simultaneous enantioseparation of two benzodiazepines, (+/-)-oxazepam and (+/-)-lorazepam was done using polymeric surfactants, poly(sodium N-undecenoxy carbonyl-L,Lleucyl-valinate) (poly-L,L-SUCLV) and determined by Chiral micellar EKC (CMEKC) coupled to ESI-MS [71] .

HPLC offers several advantages: the extraction procedures used are relatively simple, formation of derivatives is usually not necessary if the detection system is UV spectrophotometry or amperometry, and operation at ambient temperature allows the determination of nonvolatile, polar, high mass molecules or thermally labile benzodiazepines for which GC is not applicable. The strong absorption in the $230-260 \mathrm{~nm}$ regions gives sensitivity in the nano-gram range and linearity over a wide concentration range. Moreover, if the detection system is not destructive, the eluted drugs can be recovered for further examination. The feasibility of directly assaying drugs in physiological fluids using on-line preconcentration and microbore HPLC should be applied to benzodiazepines more frequently. Therefore, HPLC offers an attractive analytical alternative for the routine determination of 1,4-benzodiazepines in biological samples. 
Gas chromatography: Gas chromatography (GC) still offers the best means to confirm benzodiazepines. Most of these methods derivatized the benzodiazepines with silylating reagents [32,37] to improve spectral definition and to reduce on-column thermal degradation. Two stages of derivatization using tetramethylammonium hydroxide and propyliodide (propylation), as well as a mixture of triethylamine:propionic anhydride (propionylation) were performed for the simultaneous determination of the 23 most commonly used benzodiazepines in blood [72]. Benzodiazepines in urine samples were derivatized by using BSTFA + 1\%TMCS reagent during GC-EI-MS screening [73]. clonazepam and its metabolite 7-aminoclonazepam was derivatized using $N$-methyl- $N$-(tert-butyldimethylsilyl)trifluoroacetamide (MTBSTFA) [74]. The most favoured derivative was the conventional TMS, although the TBDM derivative offered improved spectral properties. Dimethylpolysiloxane (100\%) and $5 \%$ diphenyldimethylpolysiloxane phases were most commonly used and provided good separation capabilities for most derivatized benzodiazepines. benzodiazepines were silylated by a mixture of $\mathrm{N}$-(tert-butyldimethylsilyl)-N-methyltrifluoroacetamide, acetonitrile, ethyl acetate [46]. Conventional GC methods using fused capillary columns were most commonly used with various detection systems like flame-ionization detection (FID), nitrogen-phosphorus detection (NPD) or electron-capture detection (ECD) and mass spectrometry (MS) $[40,75]$ with the different ionization modes. Ionization modes include electron impact (EI) and chemical ionization (CI)] or scanning modes, full scan, selected-ion monitoring (SIM) or multiple-ion detection (MID). GC-MS methods were, as expected, well represented and still offer the best means to confirm benzodiazepines. EI was generally used as the ionization method with SIM, although the use of NCI provided significant sensitivity, with LODs to $0.1 \mathrm{ng} / \mathrm{mL}$ [72]. The combination of 3-step extraction and MS/MS detection provided good sensitivity of LOQ value within $1-5 \mathrm{ng} / \mathrm{g}$ [32].

Micellar liquid chromatography: A review covering theoretical treatment, optimization strategy and applications of micellar liquid chromatographic (MLC) to the determination of different groups of drug substances has been outlined by Esteve-Romero et al. [4]. Two MLC procedures [76,77] have been reported for the determination of some benzodiazepines (bromazepam, clorazepate, diltiazem, diazepam, flunitrazepam, halazepam, medazepam, nitrazepam, oxazepam and tetrazepam) using $\mathrm{C}_{18}$ columns, Eclipse XDBC $(150 \times 4.6 \mathrm{~mm}$ I.D., 5 $\mu \mathrm{m})$, Kromasil $(120 \times 4.6 \mathrm{~mm}$ I.D., $5 \mu \mathrm{m})$, and solutions containing sodium dodecylsulphate (SDS) modified with butanol or pentanol as mobile phases. Serum/pharmaceutical samples were injected directly without any pretreatment giving the LOD value of $4-18 \mathrm{ng} \mathrm{mL}^{-1}$.

Thin-layer chromatography: This is the oldest of the chromatographic techniques, but in the period covered by this review, further developments in the thin-layer chromatography (TLC) for benzodiazepines have been done. TLC with in situ scanning densitometry is rapidly gaining wide preference in pharmaceutical analysis owing to its simplicity, accuracy, cost effectiveness and the possibility of simultaneous determination of a number of samples on a single TLC plate, though it sometimes provides slightly higher values than the HPLC method. A TLC-densitometry is described for determination of diazepam, nitrazepam and flunitrazepam in tablets. The comparison of results with those obtained using HPLC showed a correlation coefficient of 0.9697 [78]. To identify and quantify diazepam, clonazepam along with other psychotropic drugs a TLCdensitometry method has been developed. Analytes were separated on precoated silica gel $60 \mathrm{~F}_{254}$ TLC plates with LOD ranged from 0.009 to $0.260 \mu \mathrm{g}$ for ultraviolet densitometric measurement and recovery ranging from 93-105\% was satisfactory [79]. A quantitative TLC method utilizing plates containing fluorescent indicator has been developed for the determination of some 1,4-benzodiazepines in pharmaceutical formulations [80].

\section{Electro-capillary Separation}

\section{Micellar electrokinetic capillary chromatography}

Micellar electrokinetic capillary chromatography (MEKC) has been successfully used to determine benzodiazepines in serum or pharmaceuticals. All methods used a sodium dodecylsulphatephosphate/borate as running buffer and one of organic modifiers such as methanol (50\%), $n$-butanol $(\sim 5 \%)$, pentanol, acetonitrile $(\sim 10 \%)$ or $1 \%$ of tetrahydrofuran [81] to assist the separation process. One method in exception used $100 \mathrm{mM}$ formic acid-1 mM TFA as buffer [82]. A micellar elektrokinetic capillary chromatography (MECC) method has been developed using a separation buffer composed of sodium tetraborate $25 \mathrm{mM}$ ( $\mathrm{pH} 9.5)$, SDS $(50 \mathrm{mM}$ ) and methanol (at least $12 \%$ ) as an organic modifier [83]. In some cases SPE [84,85] or LLE $[86,87]$ was followed for the benzodiazepines extraction. Separation was carried out at $25^{\circ} \mathrm{C}$ and $15-30 \mathrm{kV}$ by using a fused silica capillary column of 50-75 $\mu \mathrm{m}$, with multi- wavelength UV detection. Hansen and Sheribah compared the separation techniques both MEKC and MEEKC (micro emulsion electrokinetic chromatography) for the determination of impurities in bromazepam with dynamically coated fused silica capillaries [82]. Chiral micellar EKC (CMEKC) coupled to ESI-MS using polymeric surfactants, poly(sodium N-undecenoxy carbonyl-L,L-leucyl-valinate) (poly-L,L-SUCLV), was developed for the simultaneous enantioseparation of two benzodiazepines, (+/-)-oxazepam and (+/-)-lorazepam [71].

\section{Capillary electrophoresis/Capillary zone electrophoresis}

Capillary electrophoresis (CE)/Capillary zone electrophoresis (CZE) [88] is now gaining increasing acceptance as a complementary analytical technique to other separation methods such as HPLC and GC. When comparing CE with HPLC, it was found that in many applications, CE is superior to HPLC in efficiency, selectivity, peak symmetry and speed [89]. CE determination excels HPLC in that it is faster and provides results with substantial advantages, not only in expeditiousness but also in ease of operation. Due to its speed of analysis, high efficiency and low solvent and sample consumption, the technique has gained momentum in pharmaceutical and forensic research laboratories. The use of $\mathrm{CE}$ in forensic toxicology was reviewed by Tagliaro et al. [90], and the application to benzodiazepines was reviewed by Smyth and McClean [16].

1-butyl-3-methylimidazolium-based ionic liquids (ILs) and sodium dodecyl sulfate (SDS) as modifiers in the background electrolyte (BGE) for capillary electrophoresis enhanced the separation of benzodiazepines [91]. Ten abused drugs in urine were aanalyzed of by large volume sample stacking-sweeping capillary electrophoresis with an experimental design strategy. The sweeping and separating steps were completed simultaneously by phosphate buffer $(50 \mathrm{mM}, \mathrm{pH}$ 2.3) containing methanol and sodium dodecyl sulfate [92]. Hudson et al. [93] developed a comprehensive CE-DAD method to monitor over 550 basic and 100 acidic drugs in whole blood, amongst which some benzodiazepines, analyzed using $100 \mathrm{mmol} \mathrm{L}^{-1}$ phosphate run buffer of pH 2.5 and pH 9.5. Peyrin and Guillaume [94] studied chemometric approach to the treatment of ten benzodiazepines separation and peak broadening in capillary electrophoresis. Mc-Clean et al. [95] identified and determined benzodiazepines by CE-ESI-MS method aiming at 
enhancing sensitivity and repeatability of peak area and migration time. A comparison was made by McClean et al. [96] between CEUV separation and determination of 15 benzodiazepines and their metabolites and LC-ESI-ITM separation and determination. CE was shown to be superior to HPLC in terms of separation efficiency. Tomita and Okuyama [97] made a simultaneous determination of six benzodiazepines when the best conditions were obtained using $5 \mathrm{mmol}$ $\mathrm{L}^{-1}$ phosphate-borate buffers ( $\mathrm{pH} 8.5$ ) containing $50 \mathrm{mmol} \mathrm{L}^{-1} \mathrm{SDS}$ and $15 \%$ methanol. Vanhoenacker et al. [98] analysed six benzodiazepines in dynamically coated capillaries by CE-DAD, CE-MS and CE-MS ${ }^{2}$. Electrolyte was based on a commercially available buffer system covering a $\mathrm{pH}$ range from 2.5 to 9.2. Prado et al. [99] carried out $\mathrm{CE}$ analysis for the determination of diazepam in commercial and simulated tablet formulations in a bare fused-silica capillary with 75 $\mu \mathrm{m}$ i.d. and total length of $50 \mathrm{~cm}(28 \mathrm{~cm}$ to the detector). Running buffer solution was $20 \mathrm{mmol} \mathrm{L}^{-1}$ sodium tetraborate and $20 \mathrm{mmol} \mathrm{L}^{-1}$ sodium dodecylsulfate (SDS) at $\mathrm{pH} 9.23$. The LOD and LOQ were 4.24 and $12.85 \mu \mathrm{g} \mathrm{mL}^{-1}$ for CE and 1.44 and $4.36 \mu \mathrm{g} \mathrm{mL}{ }^{-1}$ for RP-HPLC demonstrating that capillary electrophoresis appears to be an adequate choice for drug quality control.

Capillary zone electrophoresis (CZE) and micro ( $\mu$ )-HPLC coupled to ESI-MS were compared in terms of sensitivity and general applicability to the quantitative analysis of pharmaceuticals in biological fluids. During the investigation of the merits and demerits of $\mu$-HPLC-MS-MS and CZE-MS-MS, for the separation and detection of midazolam and its metabolites, the combination of CZE-MS-MS was found to be superior to that of $\mu$-HPLC-MSMS with regard to LOD [100]. Comparison of CZE to non-aqueous capillary electrophoresis (NACE) for the determination of impurities in bromazepam has been performed, when the NACE was chosen as the best technique as the low solubility of the benzodiazepines in water. The NACE system showed good selectivity and detectability for the substances investigated [82]. McGrath et al. [101] studied the migration behaviour of selected 1,4-benzodiazepines and metabolites over the $\mathrm{pH}$ range $2-12$ by capillary zone electrophoresis (CZE) and method was also applied for the separation of four 1,4-benzodiazepines in a variety of pharmaceutical formulations when LODs $\left(10^{-6} \mathrm{~mol} \mathrm{~L}^{-1}\right)$ were inferior compared to those obtained by HPLC $\left(10^{-7} \mathrm{~mol} \mathrm{~L}^{-1}\right)$, GC and automated (differential pulse polarography) DPP $\left(10^{-8}-10^{-7} \mathrm{~mol} \mathrm{~L}^{-1}\right)$. However, CZE with its fast analysis time and superior efficiency can be used as a complimentary technique to HPLC for drug formulation assay.

\section{Capillary electrochromatography}

Recently, capillary electrochromatography (CEC), which combines the high efficiency of capillary zone electrophoresis and the high selectivity of HPLC, has gained much attention for the determination of benzodiazepines. Cahours et al. [102] identified five benzodiazepines using CEC method; the separation was achieved in 18 min using Tris$\mathrm{HCl}(\mathrm{pH} 8)$-acetonitrile mixture as mobile phase. CEC has been demonstrated for the separation of mixtures of benzodiazepines, corticosteroids and thiazide diuretic drugs using fused-silica capillary CEC Hypersil ODS and Apex ODS columns (33-50 $\mathrm{cm} \times 50-75 \mu \mathrm{m}, 3$ $\mu \mathrm{m})$ coupled wtih UV and ESI-MS detection [103]. The use of a 40$\mathrm{cm}$ packed bed of Reliasil 3- $\mu \mathrm{m} \mathrm{C}_{18}$ stationary phase was focused by Kapnissi and Warner [104] to separate seven benzodiazepines under the optimum conditions: a mobile phase composition of Tris- $\mathrm{HCl}(\mathrm{pH}$ 8 )-acetonitrile (60:40), an electrolyte concentration of $30 \mathrm{mM}$, and a temperature of $15^{\circ} \mathrm{C}$ with an applied voltage of $20 \mathrm{kV}$. The method was applied to the characterization of oxazepam in a standard urine sample. Sweeping technique, in conjunction with micellar electrokinetic chromatography, has considerable potential use in clinical and forensic analyses of flunitrazepam and its metabolites in urine [105]. Capillary electro chromatography, which combines the high efficiency of capillary zone electrophoresis and the high selectivity of HPLC, has gained much attention. It is applied to the characterization of oxazepam in a standard urine sample [106].

\section{Infusion nano-Electrospray Ionization-MS/MS}

Method includes three sample preparation strategies; protein precipitation of plasma with acetonitrile, de-salting of the plasma, and a combination of protein precipitation with subsequent de-salting of the dried and reconstituted extract. It may offer improvements over the conventional techniques because the nanoESI emitter is a single-use device, eliminating any chance of carryover. Its additional advantages also include that no chromatographic method development is needed and that low microliter samples are not diluted as in high-flow FIA. Midazolam fortified in human plasma was quantified using protein precipitation, off-line de-salting, and automated microchip infusion via nanoESI-MS/MS [107]. Human plasma samples $(30 \mu \mathrm{L})$ mixed with acetonitrile $(100 \mu \mathrm{L})$ containing IS (Alprazolam, $1220 \mathrm{ng} \mathrm{mL}^{-1}$ ) and $0.2 \%$ formic acid $(v / v)$ were vortex-mixed and centrifuged $(3000$ $\mathrm{rpm}, 5 \mathrm{~min}$ ). For further cleanup, the supernatant was concentrated to dryness under a gentle stream of heated nitrogen $(60 \mathrm{psi}, 30 \mathrm{C})$ in a 96-well evaporator and reconstituted in water $(20 \mu \mathrm{L})$ containing $0.1 \%$ $(v / v)$ TFA.

\section{Immunoassays}

The presence of benzodiazepines is confirmed by a number of most common immunoassay techniques which are frequently used to provide an initial test, or screen of plasma or urine $[61,67]$. Their applicability will depend on the specimens being examined (i.e. blood/ plasma/serum or urine) and the type of benzodiazepines likely to be present in the sample. Prior enzymatic hydrolysis, the conversion of glucuronide metabolites to immune reactive species is most favoured to improve the detectability. However, individual cross-reactivities of immunoassays will always need to be considered. Interestingly, radio receptor assays are becoming accepted as an alternative to immunoassays and offer the distinct advantage that detectability is not drug dependent. The available immunoassay for benzodiazepines is unable to discriminate between different benzodiazepines, owing to cross-reactivity of the antibodies used in this type of assay. Numerous commercial kits are now available including enzyme immunoassays (EIA) (e.g. EMIT) and enzyme linked inmmunosorbent assays (ELISA), fluorescent polarization immunoassays (FPIA) (e.g., SBENZ, Abbott TDx and ADx), microparticles immunoassays (e.g., TRIAGE and ONLINE), cloned enzyme donor immunoassay (CEDIA) and radio immunoassays (RIA) (DPC assays).

Janssen et al. [108] described a fluorescent receptor assay (FRA) for benzodiazepines with CLDEF as the labeled ligand for benzodiazepines (diazepam, lorazepam, and flumazenil). The time to perform a FRA and quantitation were comparable to that of radioreceptor assay (RRA). A FPIA method was developed for quantification of lorazepam in serum or plasma by the direct analysis using the TDxFLx after LLE [109]. Five commercially available immunoassays EMIT d.a.u. assay, EMIT II assay, Abbott TDx (FPIA) assay, Bio Site TRIAGE device, and the Boehringer Mannheim/Microgenics CEDIA assay were investigated for the detection of alprazolam and triazolam metabolites in urine. Enzymatic hydrolysis prior to screening increased the positive detection rate for benzodiazepines with the EMIT d.a.u. assay and FPIA [110]. A study investigated the cross-reactivity profiles and structure-reactivity 
relationships of six benzodiazepines to $\operatorname{EMIT}\left({ }^{\circ}\right)$ II Plus Benzodiazepine Assay [111].

Two immunoassay studies, SBENZ and TDx, have been conducted for the detection of flunitrazepam and metabolites in serum and urine. The relative sensitivities of the assays were, SBENZ $>$ TDx and this was explained by its higher cross-reactivity with the major metabolites [112]. Urine Samples had been found to be presumptively positive using either EMIT or Triage immunoassay methodologies [113]. The use of prior hydrolysis of urine increased the sensitivity to many of the benzodiazepines, particularly those metabolised to oxazepam. Assay was applied to urine samples for the screening of a number of benzodiazepines by the Emit ${ }^{\circ}$ d.a.u. ${ }^{\mathrm{TM}}$, when enzymatic hydrolysis before immunoassay improved its detection limits for compounds forming glucuronide conjugates [114]. Urine samples were analyzed for benzodiazepines; alprazolam, bromazepam, clonazepam, flurazepam, lorazepam nordizaepam, oxazepam, temazepam, and triazolam along with other drugs, by immunoassay screening using the cloned enzyme donor immunoassay (CEDIA) reagent [115]. Cozart ELISA was proved to be more effective than Beckman and CEDIA reagents in an improved screen and confirmation test of urine samples for preliminary detection of flunitrazepam exposure. It is because Beckman is least sensitive to detect the presence of 7-aminoflunitrazepam, and CEDIA is though sensitive most its cross-reacting characteristics toward other benzodiazepines substantially reduces its effectiveness for monitoring flunitrazepam [116]. Utilizing a bioconjugate of gold nanoparticles and enzyme-labeled antibody as a signal probe increases the sensitivity of a traditional ELISA for 7-ANZP by nearly 20 times [117].

Benzodiazepine micro-plate enzyme immunoassay kit allowed the detection of flunitrazepam and metabolites, 7-aminoflunitrazepam in urine samples after 5 to 21 days of drug administration [118]. This system was proved sufficiently sensitive for the routine screening of them in hair also by the development of extraction procedures and optimization of the immunoassay kit [119].

The advantage radioreceptor assay (RRA) technique is that all benzodiazepines and their pharmacologically active metabolites can be detected with equal sensitivity since the assay is based on a direct competition with benzodiazepine receptors. A direct RRA was presented when labelled ligand $\left[{ }^{3} \mathrm{H}\right]$-flunitrazepam, which bound to the benzodiazepine receptor with high affinity, was chosen thus yielding an adequate sensitivity to determine the benzodiazepines present in biological matrices [120]. A radioimmunoassay (RIA) was developed for a new benzodiazepine inverse agonist, 2-(isoxazol3-yl)-3,6,7,9-tetrahydro-imidazo [4,5-d] pyrano [4,3-b] pyridine monophosphate monohydrate (S-8510), in human plasma and urine [121]. Blood, fluid and/or tissue homogenates were screened for benzodiazepines along with other drugs by ELISA and by coated tube radioimmunoassay (CTR) (BARB, BE, OPI, PCP, LSD) or doubleantibody radioimmunoassay (DAR) (AMP/METH, BZD, CNB). In this study, the EIA kit performed better than the RIA method at detecting midazolam and lorazepam (not having oxazepam and nordiazepam as intermediary metabolites) [10]. The four immunoassay urine screening kits; Roche Benzodiazepine PlusKIMS assay, Microgenics CEDIA Benzodiazepine assay, Microgenics CEDIA high sensitivity assay with $\beta$-glucuronidase, and Microgenics DRI reagent ready Benzodiazepine assay, were evaluated to investigate their performance in forensic urine analysis [122-124]. In all cases confirmatory tests have been done either by HPLC-MS $[108,120,122,123]$ or GC-MS method [10,112,114-116].

Different immunoassay (IA) screening methods are compared with liquid chromatography-tandem mass spectrometry (LC-MS-MS).
Comparison draws attention to the problem of the careless use of IA tests for forensic purposes as they may provide false positive (FP), false negative (FN) results that can lead to errors of great severity [124]. These assays have proven their usefulness as screening procedures, but their shortcomings must be taken into account: False negative results can be caused by presence of conjugated metabolites as antibodies, in most currently available assays do not react significantly with conjugated metabolites. It should also be noted that the degree of crossreactivity for a given assay varies markedly from drug to drug and even between batches of antibodies from the same manufacturer. For an antibody degree of cross-reactivity can also be affected by the nature of the sample matrix. Immunoassays should only be used for the matrix recommended by manufacturer or on a matrix for which the assay has been validated.

\section{Photometric Methods}

\section{UV-spectrophotometry}

Numerous analytical techniques based on spectrophotometry have been developed for determination of benzodiazepines in various sample matrices. For example, a single-channel flow injection manifold with spectrophotometric detection has been designed and fabricated for the determination diazepam, and it has been satisfactorily applied to the quantitation of diazepam in pharmaceutical formulations with a LOD value $0.06 \mathrm{mg} \mathrm{L}^{-1}$ [125]. Recently, a derivative UVspectrophotometric method has been proposed for the determination of diazepam in tablets along with other drugs giving the satisfactory results in good agreement with those obtained by RP-HPLC [126]. Salem et al. [127] described spectrophotometric and fluorometric methods based on measuring the absorption or emission spectra in methanolic potassium hydroxide solution for determining diazepam, bromazepam and clonazepam in pharmaceutical and urine samples. Methods showed LOD value of 0.08-1.27 $\mu \mathrm{g} \mathrm{mL}^{-1}$. Two new spectrophotometric procedures have been developed for determining trace amounts of bromazepam and clonazepam derivatives in their pure and pharmaceutical dosage forms. Methods were based on forming charge transfer complexes with chloranil in chloroform or ethanol at alkaline $\mathrm{pH}$. There was no significant difference in precision between the proposed methods and HPLC official methods, when they were compared [7]. Spectrophotometric and chemometric studies on the simultaneous determination of two benzodiazepines in human plasma have been proposed that requires no preliminary separation steps [128]. A spectrophotometric method based on the acid hydrolysis of the oxazepam to a benzophenone was developed [45]. Three multivariate modelling approaches including partial least squares regression (PLS), genetic algorithm-partial least squares regression (GA-PLS), and principal components-artificial neural network (PC-ANN) analysis were investigated for the spectrophotometric determination of chlordiazepoxide in pharmaceuticals [129]. The first derivative spectrophotometric technique was applied at $231.5 \mathrm{~nm}$ for chlordiazepoxide over the concentration ranges of $2-24 \mu \mathrm{g} / \mathrm{mL}$ in pharmaceuticals [130].

\section{Fluorimetry}

A multipumping flow system (MPFS) coupled to a photodegradation unit was developed for the determination of diazepam (a benzodiazepine) in spiked alcoholic beverages by fluorimetry [131]. An automated flow injection fluorimetric determination of some benzodiazepines (oxazepam, diazepam and nitrazepam) in pharmaceutical preparations after hydrolysis with $\mathrm{H}_{2} \mathrm{SO}_{4}$ in ethanolic or methanolic medium at room temperature was 
performed which offered the LOD of $0.005-0.01 \mathrm{mg} \mathrm{mL}^{-1}$ [8]. Salem et al. [127] described spectrofluorimetric method, based on measuring absorption or emission spectra in methanolic potassium hydroxide solution, to determine diazepam, bromazepam and clonazepam (1,4-benzodiazepines) in pure forms, pharmaceutical preparations and urine samples. Method has been proved to be selective with low LOD of 5.67-16.47 $\mathrm{ng} \mathrm{mL} \mathrm{mL}^{-1}$ compared to that of $0.08-1.27 \mu \mathrm{gL} \mathrm{mL}^{-1}$ in spectrophotometric method. A spectrofluorimetric assay was described for the photodegradation products of the ansiolytic drug, alprazolam. The developed spectrofluorimetric assay allowed determination of the photodegradation products at very low concentrations $\left(\geq 10^{-5} \mathrm{M}\right)$ and it was successfully applied to the commercial tablets [132]. Another spectrofluorimetric method, which involves reduction of the target compound using $\mathrm{Zn} / \mathrm{HCl}$ at room temperature with the formation of a highly fluorescent derivative, was developed [45]. Fluorimetric methods have proved selective with low detection limits, whereas photometric methods showed relatively high detection limits.

\section{Infrared (FTIR) spectroscopy}

A quality control procedure was developed for the determination of diazepam in pharmaceuticals using Fourier transform infrared (FTIR) spectroscopy. Peak area values in the interval between 1672 and $1682 \mathrm{~cm}^{-1}$, corrected with a two points baseline established between 1850 and $1524 \mathrm{~cm}^{-1}$, were employed to quantify diazepam in samples using an external calibration line obtained with six standard solutions of diazepam dissolved in chloroform. The method provided linear range from 0.16-2.14 $\mathrm{mg} \mathrm{g}^{-1}$ with a LOD of $0.04 \mathrm{mg}$ per tablet [133].

\section{Electroanalytical Methods}

\section{Potentiometry}

The ion-selective electrode technique has the advantages of selectivity, simplicity and rapidity over the methods having shortcomings such as lack of selectivity, need of an expensive instrument or being time consuming. Salem et al. $[6,134]$ has proposed low cost and sensitive solid contact ion-selective electrodes (SC-ISE) for determining 1,4-benzodiazepines; diazepam, bromazepam and clonazepam in pure forms and in pharmaceutical preparations as well as in biological fluids. The electrodes were based on poly (vinylchloride) (PVC) or poly(esterurethane)s membranes, doped with drug-tetraphenyl borate (TPB) or drug-phosphotungstic acid (PTA) ion pair complexes as electroactive materials. The new electrodes proved highly selective with selectivity coefficients ranged from $10^{-4}-10^{-6}$ and LOD ranged from $0.1-0.63 \mu \mathrm{g}$ $\mathrm{mL}^{-1}$. The ion-selective electrode technique has been proved to be sensitive, reliable, and can be used with very good accuracy and high percentage recovery without pretreatment procedures. Cyclodextrinbased potentiometric sensors are implemented for midazolam and diazepam in pharmaceuticals. The solid-contact electrodes for midazolam and diazepam are based on polymeric membranes incorporating respectively beta-cyclodextrin and (2-hydroxiproyl)gamma-cyclodextrin as ionophores, 2-fluorophenyl 2-nitrophenyl ether as plasticizer and potassium tetrakis ( $\mathrm{p}$-chlorophenyl) borate as ionic additive [135]. Chlordiazepoxide ion-selective electrodes based on ion associates, chlordiazepoxidium-phosphomolybdate (I) and chlordiazepoxidium-phosphotungstate (II), showed a very good selectivity for the potentiometric determination of the chlordiazepoxide in pharmaceutical preparation [57].

\section{Voltammetry}

Because the 1,4-benzodiazepines are easily reduced at a mercury electrode through the two-electron reduction of the 4,5-azomethine functional group, reduction of metals (copper, gold, platinum, and palladium), as well as that of the ligands. In most situations adsorption phenomena occurred and their influence on voltammetric signals had to be carefully analyzed. The voltammetric behavior was then interpreted in terms of complex formation. Copper complexation by the 1,4-benzodiazepines was investigated using Cyclic Voltammetry $(\mathrm{CV})$ at a mercury electrode in $0.10 \mathrm{M} \mathrm{KNO}_{3}$ and $\mathrm{pH}$ 7.0-0.1 [136]. Direct square-wave voltammetry (SWV) and square-wave cathodic stripping voltammetry (SWCSV) at hanging mercury drop electrodes have been developed for determination of the psychoactive 1,4-benzodiazepines; clonazepam, bromazepam, midazolam, diazepam, medazepam, and flurazepam [137]. The formation of radical species from two benzodiazepines, loprazolam and flunitrazpam, in different media (protic, aprotic and mixed media) has been examined using cyclic voltammetry. Electron paramagnetic resonance (EPR) spectroscopy showed that both drags were reduced electrochemically to their corresponding nitro radical anions [138]. Diazepam in plasma and oxazepam in urine were determined at the optimal conditions in the voltammetric measurements using modified carbon-paste electrodes [139]. The additions-dilution solid-state electrochemical method, based on the voltammetry of microparticles approach, permits quantify, via standard additions methodology, 1,4-benzodiazepine in formulations with no need of sample dissolution using dilution with a reference electroactive compound [140]. Based on reduction behavior, a direct differential pulse voltammetric method has been developed and validated for the determination of midazolam in parenteral dosage [63]. an analytical method based on adsorptive cathodic stripping voltammetry (AdCSV) for the simultaneous determination of 1,4-benzodiazepines was developed using a hanging mercury drop electrode as a working electrode and Ringer buffer $(\mathrm{pH}$ 10.0) as a supporting electrolyte [141]. Analysis was performed with better precision, lower detection limits and much more rapidly, and the methods were applied to the analysis of commercially available tablets with minimum sample manipulation.

\section{Polarography}

The 1,4-benzodiazepines; medazepam, diazepam, flurazepam, nitrazepam, and clonazepam, were investigated using differential pulse polarography (DPP) and cyclic voltammetry (CV) at a mercury electrode in $0.10 \mathrm{M} \mathrm{KNO}_{3}$ and $\mathrm{pH} 7.0-0.1$ [136] by means of copper complexation $[94,136]$. An automated differential pulse polarography was used for the validation of CZE applied to the separation and determination of four benzodiazepines; chlorodiazepoxide, diazepam, flurazepam, nitrazepam along with omeprazole and metronidazole in pharmaceutical formulations [104].

\section{Discussion}

Thin-layer chromatography (TLC) is a valuable technique as an initial screening method to narrow the possible identities of unknown drugs in biological samples. Besides, TLC has shown little interest in the scientific publications over the last two decades. This technique still suffers from a lack of sensitivity and specificity, particularly for the newer more potent benzodiazepines. TLC with in situ scanning densitometry is rapidly gaining wide preference in pharmaceutical analysis or the use of high-performance TLC plates (HPTLC) has been shown to provide sufficient discrimination power to detect benzodiazepines.

Capillary electrophoresis (CE) has emerged as a new powerful method for rapid separations of analytes. CE, as merging techniques with very promising and interesting application of microscale analysis of drugs' binding parameters to immobilized bio-polymers 
is examined. Spectrophotometry, fluorimetry or polarography despite the advantages of convenience and speed, lacks the sensitivity and specificity, and require large amounts of sample. Most of the cases they are not applicable for simultaneous determination of benzodiazepines.

Due to the complexity of biological samples, a chromatographic separation step is required for the analysis of drugs in such samples. For these reasons attention has shifted to the development of HPLC methods for the determination of these drugs in body fluids. In term of data from the publications available in literature HPLC technique gained a wide choice (Figure 4) for the determination of benzodiazepines and their metabolites in biological samples. Spectrophotometric detection is still used for this purpose and can grant sufficient selectivity and sensitivity when coupled to suitable sample pre-treatment procedures. HPLC is able to achieve detection limits for many benzodiazepines using UV or DAD detection down to $1-2 \mathrm{ng} \mathrm{mL}^{-1}$ using 1-2 $\mathrm{mL}$ of urine or serum (blood). ECD detectors gave detection limits better than $1 \mathrm{ng} \mathrm{mL}{ }^{-1}$ from $1 \mathrm{~mL}$ of specimen, which was an order of magnitude lower than for NPD. Mass spectrometry is gaining widespread acceptance, particularly if the matrix is very complex and variable, such as human or animal blood. EI-MS offered similar sensitivity, whilst NCI-MS was capable of detection down to $0.1 \mathrm{ng} \mathrm{mL}^{-1}$. Recently liquid chromatography tandem mass spectrometry (LC-MS/MS) has been vastly developed for drug analysis in biological samples and has been proved to be robust and specific for the quantification. The reason for using tandem mass spectrometry is to increase limits of detection without the need for chemical derivatization [142].

Gas chromatographic (GC) methods offer excellent sensitivity, but possess some drawbacks over HPLC such as lengthy clean-up procedures and in some cases formation of more volatile derivatives or hydrolysis prior to analysis. Furthermore, high temperatures required to elute can lead to on-column decomposition of certain benzodiazepines. It must be emphasized that for certain benzodiazepines, HPLC still lacks the sensitivity of GC, particularly if the sensitivity range of the ultraviolet detector is restricted to 0.01 absorbance units full scale (AUFS). In particular, the combination of HPLC with MS appears to offer an important alternative to conventional GC-MS for the identification new metabolites of the drugs.

Electrokinetic micellar chromatography has also been shown to be capable of the analysis of benzodiazepines in urine. For the separation of enantiomers of benzodiazepines HPLC methods have been described and proved to be suitable.

Chromatography can be avoided by the use of enzyme multiplied immunoassay techniques, but these are not specific for each drug. A range of immunoassay procedures using EIA, ELISA, FPIA, agglutination or kinetic interaction of microparticles, or RIA methods are now available. Cross reactivities to benzodiazepines are variable such that no one kit will recognize all benzodiazepines and their relevant metabolites at concentrations likely to be encountered during therapeutic use. Prior hydrolysis of urine to convert glucuronide metabolites to immunoreactive substances improves detection limits for many benzodiazepines. However, it is relatively non-specific, time consuming and provides only semi-quantitative data.

Solvent extraction technique using a variety of solvents is still popular and offer acceptable recoveries and lack of significant interference from other substances as shown in Figure 3. Describing solid phase extraction procedures a number of papers have been published and SPE gained the second position. Direct injection of specimens into a HPLC column with back flushing was also successfully described. A number of modern extraction techniques minimizing the use of organic solvent are described that are supposed to be environmentally friendly technologies e.g. SPME, LPME, DLLME. Search for such types of techniques by analysts are gradually increasing to avoid the health hazard conventional LLE.

\section{Conclusion}

Benzodiazepines are currentlyamong the most frequently prescribed drugs all over the world. They act as anxiolytics, sedatives, hypnotics, amnesics, antiepileptics and muscle relaxants. Benzodiazepines are often used for the treatment of epilepsy, convulsions, and many psychiatric disorders. The widespread use of this class of drugs has occasionally raised concern about recreational benzodiazepine abuse and has led to the erroneous impression that benzodiazepines have a relatively high abuse liability among recreational drug users. Therefore, the separation and identification of these compounds is of great interest. Methods reported in this paper allowed for a simple, accurate, rapid and reproducible quantification of BDZs in pharmaceutical formulations as well as biological samples. The described approaches might be very useful for pharmaceutical laboratory and researches in which extensive benzodiazepines analyses are performed. In general, the separation of benzodiazepines is performed using highperformance liquid chromatography (HPLC). LC-MS was proved to be the most useful tool in sensitivity terms for identification of $\mathrm{ng} \mathrm{mg}^{-1}$ levels of benzodiazepines in human hair. Most methods are based on liquid chromatography, which provides wide applicability and good analytical performance granting high precision, accuracy and feasibility. Chromatographic techniques, particularly HPLC and GC, are most commonly used to identify specific benzodiazepines present in a sample, sometimes initially screened by one of the immunoassay-based kit methods. Several radioreceptor assays have now been published and show good sensitivity and specificity to benzodiazepines and offer the advantage (over immunoassay) of being able to detect these drugs with equal sensitivity. The ultimate choice of an assay method for benzodiazepines determination will be considered by the application (routine monitoring, pharmacokinetics, overdose, forensic medicine) and characteristics of the benzodiazepine, the expertise of the analyst, the equipment available, the desired sensitivity and specificity, and the time involved in method development or adaptation and validation.

\section{References}

1. Kosjek T, Perko S, Zupanc M, Zanoški Hren M, Landeka Dragičević T, et al. (2012) Environmental occurrence, fate and transformation of benzodiazepines in water treatment. Water Res 46: 355-368.

2. Toyóoka T, Kumaki Y, Kanbori M, Kato M, Nakahara Y (2003) Determination of hypnotic benzodiazepines (alprazolam, estazolam, and midazolam) and their metabolites in rat hair and plasma by reversed-phase liquid-chromatography with electrospray ionization mass spectrometry. J Pharm Biomed Anal 30 1773-1787.

3. Höld KM, Crouch DJ, Wilkins DG, Rollins DE, Maes RA (1997) Detection of alprazolam in hair by negative ion chemical ionization mass spectrometry. Forensic Sci Int 84: 201-209.

4. Esteve-Romero J, Carda-Broch S, Gil-Agust M, Capella-Peiro M, Bose D (2005) Micellar liquid chromatography for the determination of drug materials in pharmaceutical preparations and biological samples. Trends Anal Chem 24: $75-91$.

5. Berzas JJ, Castañeda G, Pinilla MJ (2002) Determination of Clobazam Clorazepate, Flurazepam and Flunitrazepam in pharmaceutical preparations. Talanta 57: 333-341.

6. Salem AA, Barsoum BN, Izake EL (2003) Potentiometric determination of diazepam, bromazepam and clonazepam using solid contact ion-selective electrodes. Anal Chim Acta 498: 79-91. 
Citation: Uddin MN, Samanidou VF, Papadoyannis IN (2014) An Overview on Total Analytical Methods for the Detection of 1,4-Benzodiazepines. Pharm Anal Acta 5: 303. doi:10.4172/2153-2435.1000303

7. Salem AA, Barsoum BN, Izake EL (2002) Determination of bromazepam and clonazepam in pure and Pharmaceutical dosage forms using chloranil as a charge transfer complexing agent. Anal lett 35: 1631-1648.

8. Dolejsová J, Solich P, Polydorou CK, Koupparis MA, Efstathiou CE (1999) Flowinjection fluorimetric determination of 1,4-benzodiazepines in pharmaceutical formulations after acid hydrolysis. J Pharm Biomed Anal 20: 357-362.

9. Tomita M, Okuyama T (1996) Application of capillary electrophoresis to the simultaneous screening and quantitation of benzodiazepines. J Chromatogr B Biomed Appl 678: 331-337.

10. Moore KA, Werner C, Zannelli RM, Levine B, Smith ML (1999) Screening postmortem blood and tissues for nine cases of drugs of abuse using automated microplate immunoassay. Foren Sci Int 106: 93-102.

11. Kintz $P$ (2007) Bioanalytical procedures for detection of chemical agents in hair in the case of drug-facilitated crimes. Anal Bioanal Chem 388: 1467-1474.

12. Thieme D, Sachs H (2003) Improved screening capabilities in forensic toxicology by application of liquid chromatography-tandem mass spectrometry. Anal Chim Acta 492:171-186.

13. Drummer OH (2006) Drug testing in oral fluid. Clin Biochem Rev 27: 147-159.

14. Nakamura M (2011) Analyses of benzodiazepines and their metabolites in various biological matrices by LC-MS(/MS). Biomed Chromatogr 25: 12831307.

15. Sachs H, Kintz $P$ (1998) Testing for drugs in hair. Critical review of chromatographic procedures since 1992. J Chromatogr B Biomed Sci Appl 713: 147-161.

16. Smyth WF, McClean S (1998) A critical evaluation of the application of capillary electrophoresis to the detection and determination of 1,4-benzodiazepine tranquilizers in formulations and body materials. Electrophoresis 19: 28702882.

17. Bertucci C, Bartolini M, Gotti R, Andrisano V (2003) Drug affinity to immobilized target bio-polymers by high-performance liquid chromatography and capillary electrophoresis. J Chromatogr B Analyt Technol Biomed Life Sci 797: 111-129.

18. Hefnawy MM (2002) Analysis of certain tranquilizers in biological fluids. $J$ Pharm Biomed Anal 27: 661-678.

19. Drummer $\mathrm{OH}$, Ranson DL (1996) Sudden death and benzodiazepines. Am J Forensic Med Pathol 17: 336-342.

20. Samanidou VF, Uddin MN, Papadoyannis IN (2009) Benzodiazepines: sample preparation and HPLC methods for their determination in biological samples. Bioanalysis 1: 755-784.

21. Uddin MN, Samanidou VF, Papadoyannis IN (2013) Bio-sample preparation and gas chromatographic determination of benzodiazepines--a review. J Chromatogr Sci 51: 587-598.

22. Uddin MN, Samanidou VF, Papadoyannis IN (2010) Stability study of six 1,4 -benzodiazepines in plasma, urine and saliva stored at $-200^{\circ} \mathrm{C}$. Chaing Mai J Sci $37:$ 451-463.

23. Calisto V, Domingues MR, Esteves VI (2011) Photodegradation of psychiatric pharmaceuticals in aquatic environments--kinetics and photodegradation products. Water Res 45: 6097-6106.

24. Moosmann B, Huppertz LM, Hutter M, Buchwald A, Ferlaino S, et al. (2013) Detection and identification of the designer benzodiazepine flubromazepam and preliminary data on its metabolism and pharmacokinetics. J Mass Spectrom 48: 1150-1159.

25. Mandrioli R, Mercolini L, Raggi MA (2008) Benzodiazepine metabolism: an analytical perspective. Curr Drug Metab 9: 827-844.

26. Kronstrand R, Forsman M, Roman M (2013) A screening method for 30 drugs in hair using ultrahigh-performance liquid chromatography time-of-flight mass spectrometry. Ther Drug Monit 35: 288-295.

27. Favretto D, Vogliardi S, Stocchero G, Nalesso A, Tucci M, et al. (2011) High performance liquid chromatography-high resolution mass spectrometry and micropulverized extraction for the quantification of amphetamines, cocaine, opioids, benzodiazepines, antidepressants and hallucinogens in $2.5 \mathrm{mg}$ hair samples. J of Chrom A 1218: 6583-6595.

28. Salomone A, Gerace E, Brizio P, Gennaro MC, Vincenti M (2011) A fas liquid chromatography-tandem mass spectrometry method for determining benzodiazepines and analogues in urine. Validation and application to real cases of forensic interest. J Pharm and Biomed Anal 56: 582-591.

29. Uddin MN, Samanidou VF, Papadoyannis IN (2010) Sample preparation overview for the chromatographic determination of 1,4-benzodiazepines in biological matrices (Chapter 7), Reviews in Pharmaceutical and Biomedical Analysis, Editors: Constantinos K, Zacharis and Paraskevas D, Tzanavaras. 84-107, Bentham Science Publishers Ltd.

30. Déglon J, Versace F, Lauer E, Widmer C, Mangin P, et al. (2012) Rapid LC-MS/ MS quantification of the major benzodiazepines and their metabolites on dried blood spots using a simple and cost-effective sample pretreatment. Bioanalysis 4:1337-1350.

31. Kiss B, Bogdan C, Pop A, Loghin F (2012) A rapid UPLC-MS/MS method for simultaneous determination of flunitrazepam, 7-aminoflunitrazepam, methadone and EDDP in human, rat and rabbit plasma. Talanta 99: 649-659.

32. Cartiser N, Bévalot F, Le Meur C, Gaillard Y, Malicier D, et al. (2011) Gas chromatography-tandem mass spectrometry assay for the quantification of four benzodiazepines and citalopram in eleven postmortem rabbit fluids and tissues, with application to animal and human samples. J of Chrom B 879: 2909-2918.

33. Li P, Han H, Zhai X, He W, Sun L, et al. (2012) Simultaneous HPLC-UV determination of ketamine, xylazine, and midazolam in canine plasma. Chromatogr Sci 50: 108-113.

34. Ming DS, Heathcote $\mathrm{J}$ (2011) A rapid and accurate UPLC/MS/MS method for the determination of benzodiazepines in human urine. J Chromatogr B Analyt Technol Biomed Life Sci 879: 421-428.

35. Uddin MN, Samanidou VF, Papadoyannis IN (2009) HPLC method for simultaneous determination of 1,4-benzodiazepines and tricyclic antidepressants in pharmaceutical formulations and saliva- a useful tool in medicinal chemistry. J Liq Chromatogr Rel Technol 32: 1475-1504.

36. Uddin MN, Samanidou VF, Papadoyannis IN (2008) Validation of SPE-HPLC determination of 1,4-benzodiazepines and metabolites in blood plasma, urine and saliva. J Sep Sci 31: 3704-3717.

37. Kaartama R, Jarho P, Savolainen J, Kokki H, Lehtonen M (2011) Determination of midazolam and 1-hydroxymidazolam from plasma by gas chromatography coupled to methane negative chemical ionization mass spectrometry after sublingual administration of midazolam. J Chrom B 879: 1668-1676.

38. Wang KC, Cheng MC, Hsieh CL, Hsu JF, Wu JD, et al. (2013) Determination of nimetazepam and 7-aminonimetazepam in human urine by using liquid chromatography-tandem mass spectrometry. Forensic Sci Int 224: 84-89.

39. Morini L, Vignali C, Polla M, Sponta A, Groppi A (2012) Comparison of extraction procedures for benzodiazepines determination in hair by LC-MS/MS. Forensic Sci Int 218: 53-56.

40. Langel K, Gunnar T, Ariniemi K, Rajamäki O, Lillsunde P (2011) A validated method for the detection and quantitation of 50 drugs of abuse and medicinal drugs in oral fluid by gas chromatography-mass spectrometry. J Chromatogr B Analyt Technol Biomed Life Sci 879: 859-870.

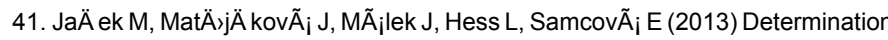
of midazolam in rabbit plasma by GC and LC following nasal and ocular administration. J Sep Sci 36: 3366-3371.

42. Mirnaghi FS, Monton MRN, Pawliszyn J (2012) Thin-film octadecyl-silica glass coating for automated 96 -blade solid-phase microextraction coupled with liquid chromatography-tandem mass spectrometry for analysis of benzodiazepines. J Chrom A 1246: 2-8.

43. Rezaei F, Yamini Y, Moradi M, Daraei B (2013) Supramolecular solvent-based hollow fiber liquid phase microextraction of benzodiazepines. Anal Chim Acta 804: 135-142.

44. Bjørk MK, Simonsen KW, Andersen DW, Dalsgaard PW, Sigurðardóttir SR et al.(2013) Quantification of 31 illicit and medicinal drugs and metabolites in whole blood by fully automated solid-phase extraction and ultra-performance liquid chromatography-tandem mass spectrometry. Anal Bioanal Chem 405 : 2607-2617.

45. Tabrizi AB, Harasi M (2012) Applying cloud point extraction technique for the extraction of oxazepam from human urine as a colour or fluorescent derivative prior to spectroscopic analysis methods. Drug Test Anal 4: 145-150.

46. Karlonas N, Padarauskas A, Ramanavicius A, Ramanaviciene A (2013) Mixed 
Citation: Uddin MN, Samanidou VF, Papadoyannis IN (2014) An Overview on Total Analytical Methods for the Detection of 1,4-Benzodiazepines. Pharm Anal Acta 5: 303. doi:10.4172/2153-2435.1000303

mode SPE for a multi-residue analysis of benzodiazepines in whole blood using rapid GC with negative-ion chemical ionization MS. J Sep Sci 36: 1437-1445.

47. Verplaetse R, Cuypers E, Tytgat J (2012) The evaluation of the applicability of a high $\mathrm{pH}$ mobile phase in ultrahigh performance liquid chromatography tandem mass spectrometry analysis of benzodiazepines and benzodiazepinelike hypnotics in urine and blood. J Chromatogr A 1249: 147-154.

48. Westland JL, Dorman FL (2013) QuEChERS extraction of benzodiazepines in biological matrices. J Pharm Anal 3: 509-517.

49. Miria L, Jalalia F (2013) Dispersive liquid-liquid micro-extraction as a sample preparation method for clonazepam analysis in water samples and pharmaceutical preparations. J Reports in Pharm Sci 2: 103-110.

50. Ghobadi M, Yamini Y, Ebrahimpour B (2014) SPE coupled with dispersive liquid-liquid microextraction followed by GC with flame ionization detection for the determination of ultra-trace amounts of benzodiazepines. J Sep Sci 37 287-294.

51. Fernández P, González C, Pena MT, Carro AM, Lorenzo RA (2013) A rapid ultrasound-assisted dispersive liquid-liquid microextraction followed by ultraperformance liquid chromatography for the simultaneous determination of seven benzodiazepines in human plasma samples. Anal Chim Acta 767: 88-96.

52. Khodadoust S, Ghaedi M (2013) Optimization of dispersive liquid-liquid microextraction with central composite design for preconcentration of chlordiazepoxide drug and its determination by HPLC-UV. J Sep Sci 36: 1734 1742.

53. Wietecha-PosÅ, uszny $R$, WoÅniakiewicz M, Garbacik A, ChÄ ${ }^{T M}$ sy $P$, KoÅ cielniak P (2013) Application of microwave irradiation to fast and efficient isolation of benzodiazepines from human hair. J Chromatogr A 1278: 22-28.

54. Su Q, Zeng C, Tang Y, Finlow DE, Cao M (2012) Evaluation of diazepammolecularly imprinted microspheres for the separation of diazepam and its main metabolite from body fluid samples. J Chromatogr Sci 50: 608-614.

55. Sruthi A, Tejaswi P, Thanuja N, Kumar DS, Vivek Sagar P (2013) Simple RPHPLC method for estimation of diazepam in tablet dosage form. J Pharmacy Res 6: 140-144.

56. Uddin MN, Samanidou VF, Papadoyannis IN (2011) Simultaneous Determination of 1,4-Benzodiazepines and 4 Tricyclic Antidepressants in Saliva after Sequential SPE Elution by the Same HPLC Conditions. J Chinese Chem Soc 58: $142-154$

57. Mistry K, Grinberg N (2005) Application of monolithic columns in high performance liquid chromatography. J Liquid Chrom and Related Tech 28: 1055-1074.

58. Pok PR, Mauras M, De Saint Léger MN, Kuhlmann E, Charpenel-Durat C, et al. (2010) Blood concentrations of clobazam and norclobazam in a lethal case involving clobazam, meprobamate and clorazepate. Leg Med (Tokyo) 12: 300304

59. Verweij AMA, Hordijk ML, Lipman PJL (1996) Liquid chromatographicthermospray tandem mass spectrometric quantitative analysis of some drugs with hypnotic, sedative and tranquillising properties in whole blood. J. Chromatogr B 686: 27-34.

60. Marin SJ, McMillin GA (2010) LC-MS/MS analysis of 13 benzodiazepines and metabolites in urine, serum, plasma, and meconium. Methods Mol Biol 603: 89-105.

61. Lee H, Lee J, Lin SY, Lin YY, Wu CF, et al. (2013) Simultaneous quantification of urine flunitrazepam, nimetazepam and nitrazepam by using liquid chromatography tandem mass spectrometry. Clinica Chimica Acta 420: 134-139.

62. Rust KY, Baumgartner MR, Meggiolaro N, Kraemer T (2012) Detection and validated quantification of 21 benzodiazepines and 3 "z-drugs" in human hair by LC-MS/MS. Forensic Sci Int 215: 64-72.

63. Jainn R, Yadav RK (2012) Voltammetric behavior of sedative drug midazolam at glassy carbon electrode in solubilized systems. J Pharm Anal 2: 123-129.

64. de Jager AD, Bailey NL (2011) Online extraction LC-MS/MS method for the simultaneous quantitative confirmation of urine drugs of abuse and metabolites: Amphetamines, opiates, cocaine, cannabis, benzodiazepines and methadone. J Chrom B 879: 2642-2652.

65. Xiang $P$, Sun $Q$, Shen $B$, Chen $P$, Liu W, et al. (2011) Segmental hair analysis using liquid chromatography-tandem mass spectrometry after a single dose of benzodiazepines. Forensic Sci Int 204: 19-26.
66. Kalíková K, Riesová M, Chudoba R, Schmid MG, Tesarová E (2011) Separation and Quantification of 1,4-benzodiazepines: HPLC versus CZE. Croat Chem Acta 84: 367-373.

67. Tsai IL, Weng TI, Tseng YJ, Tan HK, Sun HJ, et al. (2013) Screening and confirmation of 62 drugs of abuse and metabolites in urine by ultrahigh-performance liquid chromatography-quadrupole time-of-flight mass spectrometry. J Anal Toxicol 37: 642-651.

68. Gunn J, Kriger S, Terrell AR (2010) Simultaneous determination and quantification of 12 benzodiazepines in serum or whole blood using UPLC/MS/ MS. Methods Mol Biol 603: 107-119.

69. Sauve EN, Langødegård M, Ekeberg D, Øiestad AM (2012) Determination of benzodiazepines in ante-mortem and post-mortem whole blood by solidsupported liquid-liquid extraction and UPLC-MS/MS. J Chromatogr B Analyt Technol Biomed Life Sci 883-884: 177-88.

70. Birkler RID, Telving R, Ingemann-Hansen O, Charles AV, Johannsen M, et al (2012) Screening analysis for medicinal drugs and drugs of abuse in whole blood using ultra-performance liquid chromatography time-of-flight mass spectrometry (UPLC-TOF-MS)-Toxicological findings in cases of alleged sexual assault. Forensic Sci Inter 222: 154-161.

71. Hou J, Rizvi SA, Zheng J, Shamsi SA (2006) Application of polymeric surfactants in micellar electrokinetic chromatography-electrospray ionization mass spectrometry of benzodiazepines and benzoxazocine chiral drugs. Electrophoresis 27: 1263-1275.

72. Papoutsis II, Athanaselis SA, Nikolaou PD, Pistos CM, Spiliopoulou CA et al. (2010) Development and validation of an El-GC-MS method for the determination of benzodiazepine drugs and their metabolites in blood: applications in clinical and forensic toxicology. J Pharm Biomed Anal 52: 609614

73. Adamowicz $\mathrm{P}, \mathrm{KaA}$ a $\mathrm{M}$ (2010) Simultaneous screening for and determination of 128 date-rape drugs in urine by gas chromatography-electron ionizationmass spectrometry. Forensic Sci Int 198: 39-45.

74. Karlonas N, Padarauskas A, Ramanavicius A, Minkuviene Z, Ramanaviciene A (2012) Rapid and highly sensitive determination of clonazepam and 7-aminoclonazepam in whole blood using gas chromatography with negativeion chemical ionization mass spectrometry. Chemija 23: 91-99.

75. Gautam L, Sharratt SD, Cole MD (2014) Drug facilitated sexual assault: detection and stability of benzodiazepines in spiked drinks using gas chromatography-mass spectrometry. PLoS One 9: e89031.

76. Capella-Peiró ME, Bose D, Martinavarro-Domínguez A, Gil-Agustí M, EsteveRomero J (2002) Direct injection micellar liquid chromatographic determination of benzodiazepines in serum. J Chromatogr B Analyt Technol Biomed Life Sci 780: 241-249.

77. Gil-Agustí M, Carda-Broch S, Garcia-Alvarez-Coque MC, Esteve-Romero J (2000) Use of micellar mobile phases for the chromatographic determination of clorazepate, diazepam, and diltiazem in pharmaceuticals. J Chromatogr Sci 38: $521-527$.

78. Bakavoli M, Kaykhaii M (2003) Quantitative determination of diazepam nitrazepam and flunitrazepam in tablets using thin-layer chromatographydensitometry technique. J Pharm Biomed Anal 31: 1185-1189.

79. MaÅslanka A, Krzek J (2005) Densitometric high performance thin-laye chromatography identification and quantitative analysis of psychotropic drugs. J AOAC Int 88: 70-79.

80. Sarbu C, Cimpan G (1996) Determination of 1, 4-benzodiazepines by quantitative TLC A regression study employing the ladder of power. J Plan Chromatogr Mod TLC 9: 126-128.

81. Renou-Gonnord MF, David K (1996) Optimized micellar electrokinetic chromatographic separation of benzodiazepines. J ChromatogrA 735: 249-261.

82. Hansen SH, Sheribah ZA (2005) Comparison of CZE, MEKC, MEEKC and non-aqueous capillary electrophoresis for the determination of impurities in bromazepam. J Pharm Biomed Anal 39: 322-327.

83. Hancu G, Gáspár A, Gyéresi A (2007) Separation of 1,4-benzodiazepines by micellar elektrokinetic capillary chromatography. J Biochem Biophys Methods 69: 251-259.

84. Berzas JJ, Castañeda G, Pinilla MJ (2002) Determination of Clobazam, Clorazepate, Flurazepam and Flunitrazepam in pharmaceutical preparations. Talanta 57: 333-341. 
Citation: Uddin MN, Samanidou VF, Papadoyannis IN (2014) An Overview on Total Analytical Methods for the Detection of 1,4-Benzodiazepines. Pharm Anal Acta 5: 303. doi:10.4172/2153-2435.1000303

85. Mikami E, Goto T, Ohno T, Oka H, Kanamori H (2005) Simultanous determination of seven benzodiazepines in dietery supplements as adulterants using HPLC and it's application to identification system to diazepam. J Health Sci 51: 278-283.

86. Bishop SC, Lerch M, McCord BR (2004) Micellar electrokinetic chromatographic screening method for common sexual assault drugs administered in beverages. Forensic Sci Int 141: 7-15.

87. Imazawa M, Hatanaka Y (1997) Micellar electrokinetic capillary chromatography of benzodiazepine antiepileptics and their desmethyl metabolites in blood. $\mathrm{J}$ Pharm Biomed Anal 15: 1503-1508.

88. Mansour MF, El-Kady EF, El-Guindi NM, El-Moghazy SM, Van Schepdael A (2013) Simultaneous determination of chlordiazepoxide and selected antidepressants using CZE. J Sep Sci 36: 3432-3439.

89. Altria KD (1996) Capillary Electrophoresis Guidebook: Principles, Operation and Applications. Humana Press, Totowa, 64, 85-86, 88-89 [Methods in Molecular Biology Series, 52]

90. Tagliaro F, Turrina S, Pisi P, Smith FP, Marigo M (1998) Determination of illicit and/or abused drugs and compounds of forensic interest in biosamples by capillary electrophoretic/electrokinetic methods. J Chromatogr B Biomed Sci Appl 713: 27-49.

91. Su HL, Kao WC, Lin KW, Lee CY, Hsieh YZ (2010) 1-Butyl-3-methylimidazoliumbased ionic liquids and an anionic surfactant: excellent background electrolyte modifiers for the analysis of benzodiazepines through capillary electrophoresis. J Chromatogr A 1217: 2973-2979.

92. Ho YH, Wang CC, Hsiao YT, Ko WK, Wu SM (2013)Analysis of ten abused drugs in urine by large volume sample stacking-sweeping capillary electrophoresis with an experimental design strategy. J Chromatogr A 1295: 136-141.

93. Hudson JC, Golin M, Malcolm M, Whiting CF (1998) Capillary zone electrophoresis in a comprehensive screen for drugs of forensic interest in whole blood: an update. Forensic Sci J 31: 1-29.

94. Peyrin E, Guillaume YC (1999) Chemometric approach to the treatment of benzodiazepine separation and peak broadening in capillary electrophoresis. J Chromatogr A 849: 563-573.

95. McClean S, O'Kane EJ, Smyth WF (2000) The identification and determination of selected 1,4-benzodiazepines by an optimised capillary electrophoresiselectrospray mass spectrometric method. Electrophoresis 21: 1381-1389.

96. McClean S, ÓKane E, Hillis J, Smyth WF (1999) Determination of 1,4-benzodiazepines and their metabolites by capillary electrophoresis and high-performance liquid chromatography using ultraviolet and electrospray ionisation mass spectrometry. J Chromatogr A 838: 273-291.

97. Tomita M, Okuyama T (1996) Application of capillary electrophoresis to the simultaneous screening and quantitation of benzodiazepines. J Chromatogr $\mathrm{B}$ Biomed Appl 678: 331-337.

98. Vanhoenacker G, de l'Escaille F, De Keukeleire D, Sandra P (2004) Analysis of benzodiazepines in dynamically coated capillaries by CE-DAD, CE-MS and CE-MS2. J Pharm Biomed Anal 34: 595-606.

99. Prado MSA, Steppe M, Tavares MFM, Kedor-Hackmann ERM, Santoro MIRM (2005) Comparison of capillary electrophoresis and reversed-phase liquid chromatography methodologies for determination of diazepam in pharmaceutical tablets. J Pharm Biomed Anal 37: 273-279.

100.Lausecker B, Hopfgartner G, Hesse M (1998) Capillary electrophoresis-mass spectrometry coupling versus micro-high-performance liquid chromatographymass spectrometry coupling: a case study. J Chromatogr B Biomed Sci Appl 718: 1-13.

101.McGrath G, McClean S, OKane E, Smyth WF, Tagliaro F (1996) Study of the capillary zone electrophoretic behaviour of selected drugs, and its comparison with other analytical techniques for their formulation assay. J Chromatogr A 735: $237-247$

102. Cahours X, Morin Ph, Dreux M (1999) Influence of ionic strength and organic modifier on performance in capillary electrochromatography on phenyl silica stationary phase. J Chromatogr A 845: 203-216.

103. Taylor MR, Teale P (1997) Gradient capillary electrochromatography of drug mixtures with UV and electrospray ionisation mass spectrometric detection. J Chromatogr A 768: 89-95.

104. Kapnissi CP, Warner IM (2004) Separation of benzodiazepines using capillary electrochromatography. J Chromatogr Sci 42: 238-244.
105. Huang CW, Jen HP, Wang RD, Hsieh YZ (2006) Sweeping technique combined with micellar electrokinetic chromatography for the simultaneous determination of flunitrazepam and its major metabolites. J Chromatogr A 1110: $240-244$.

106. Kapnissi CP, Warner IM (2004) Separation of benzodiazepines using capillary electrochromatography. J Chromatogr Sci 42: 238-244.

107. Kapron JT, Pace E, Van Pelt CK, Henion J (2003) Quantitation of midazolam in human plasma by automated chip-based infusion nanoelectrospray tandem mass spectrometry. Rapid Commun Mass Spectrom 17: 2019-2026.

108. Janssen MJ, Ensing K, de Zeeuw RA (2001) A fluorescent receptor assay for benzodiazepines using coumarin-labeled desethylflumazenil as ligand. Anal Chem 73: 3168-3173.

109. Agbuya PG, Li L, Miles MV, Zaritsky AL, Morris AD (1996) Development of a fluorescence polarization immunoassay for lorazepam quantification. Ther Drug Monit 18: 194-199.

110. Fraser AD, Meatherall $R$ (1996) Comparative evaluation of five immunoassays for the analysis of alprazolam and triazolam metabolites in urine: effect of lowering the screening and GC-MS cut-off values. J Anal Toxicol 20: 217-223.

111. Bertol E, Vaiano F, Furlanetto S, Mari F (2013) Cross-reactivities and structurereactivity relationships of six benzodiazepines to EMIT(®) immunoassay. J Pharm Biomed Anal 84: 168-172.

112. Snyder H, Schwenzer KS, Pearlman R, McNally AJ, Tsilimidos M, et al. (2001) Serum and urine concentrations of flunitrazepam and metabolites, after a single oral dose, by immunoassay and GC-MS. J Anal Toxicol 25: 699-704.

113. Valentine JL, Middleton R, Sparks C (1996) Identification of urinary benzodiazepines and their metabolites: comparison of automated HPLC and GC-MS after immunoassay screening of clinical specimens. J Anal Toxicol 20: 416-424.

114. Rasanen I, Neuvonen M, Ojanperä I, Vuori E (2000) Benzodiazepine findings in blood and urine by gas chromatography and immunoassay. Forensic $\mathrm{Sci}$ Int 112: 191-200.

115. Fraser AD, Zamecnik J, Keravel J, McGrath L, Wells J (2001) Experience with urine drug testing by the Correctional Service of Canada. Forensic Sci Int 121 16-22.

116. Wang PH, Liu C, Tsay WI, Li JH, Liu RH, et al. (2002) Improved screen and confirmation test of 7-aminoflunitrazepam in urine specimens for monitoring flunitrazepam (Rohypnol) exposure. J Anal Toxicol 26: 411-418.

117. Peng C, Duan X, Song S, Xue F (2013) Parts per trillion detection of 7-aminonitrazepam by nano-enhanced ELISA. Int J Mol Sci 14: 19474-19483.

118. Negrusz A, Moore CM, Stockham TL, Poiser KR, Kern JL, et al. (2000) Elimination of 7-aminoflunitrazepam and flunitrazepam in urine after a single dose of Rohypnol. J Forensic Sci 45: 1031-1040.

119. Negrusz A, Moore C, Deitermann D, Lewis D, Kaleciak K, et al. (1999) Highly sensitive micro-plate enzyme immunoassay screening and $\mathrm{NCl}-\mathrm{GC}-\mathrm{MS}$ confirmation of flunitrazepam and its major metabolite 7-aminoflunitrazepam in hair. J Anal Toxicol 23: 429-435.

120. de Jong LAA, Verwey B, Essink G, Muntendam A, Zitman FG, et al. (2004) Determination of the benzodiazepine plasma concentrations in suicidal patients using a radioreceptor assay. J Anal Toxicol 28: 587-592.

121. Inoue H, Maeno Y, Iwasa M, Matoba R, Nagao M (2000) Screening and determination of benzodiazepines in whole blood using solid-phase extraction and gas chromatography/mass spectrometry. Forensic Sci Int 113: 367-373.

122. DeRienz RT, Holler JM, Manos ME, Jemionek J, Past MR (2008) Evaluation of four immunoassay screening kits for the detection of benzodiazepines in urine. J Anal Toxicol 32: 433-437.

123. Kominami G, Nakamura M, Chomei N, Takada S (1999) Radioimmunoassay for a novel benzodiazepine inverse agonist, S-8510, in human plasma and urine. J Pharm Biomed Anal 20: 145-153.

124. Bertol E, Vaiano F, Borsotti M, Quercioli M, Mari F (2013) Comparison of immunoassay screening tests and LC-MS-MS for urine detection of benzodiazepines and their metabolites: results of a national proficiency test. J Anal Toxicol 37: 659-664.

125. Liawruangrath S, Makchit J, Liawruangrath B (2006) A simple flow injection spectrophotometric procedure for the determination of diazepam in pharmaceutical formulation. Anal Sci 22: 127-130. 
Citation: Uddin MN, Samanidou VF, Papadoyannis IN (2014) An Overview on Total Analytical Methods for the Detection of 1,4-Benzodiazepines. Pharm Anal Acta 5: 303. doi:10.4172/2153-2435.1000303

126. Ferreyra CF, Ortiz CS (2002) Simultaneous spectrophotometric determination of phenilpropanolamine $\mathrm{HCL}$, caffeine and diazepam in tablets. J Pharm Biomed Anal 29: 811-818.

127. Salem AA, Barsoum BN, Izake EL (2004) Spectrophotometric and fluorimetric determination of diazepam, bromazepam and clonazepam in pharmaceutical and urine samples. Spectrochim Acta A Mol Biomol Spectrosc 60: 771-780.

128. Riahi S, Bagherzadeh K, Davarkhah N, Ganjali MR, Norouzi P (2011) Spectrophotometric and chemometric studies on the simultaneous determination of two benzodiazepines in human plasma. Materials Sci Eng C 31: 992-996.

129. Khoshayand MR, Abdollahi H, Moeini A, Shamsaie A, Ghaffari A (2010) Simultaneous spectrophotometric determination of chlordiazepoxide and clidinium using multivariate calibration techniques. Drug Test Anal 2: 430-435.

130. Patel SK, Patel NJ (2010) Simultaneous determination of imipramine hydrochloride and chlordiazepoxide in pharmaceutical preparations by spectrophotometric, RP-HPLC, and HPTLC methods. J AOAC Int 93: 904-910.

131. Ribeiro DS, Prior JA, Santos JL, Lima JL (2010) Automated determination of diazepam in spiked alcoholic beverages associated with drug-facilitated crimes. Anal Chim Acta 668: 67-73.

132. Nudelman NS, Gallardo Cabrera C (2002) Spectrofluorimetric assay for the photodegradation products of alprazolam. J Pharm Biomed Anal 30: 887-893.

133. Moros J, Garrigues S, de la Guardia M (2007) Quality control Fourier transform infrared determination of diazepam in pharmaceuticals. J Pharm Biomed Anal 43: 1277-1282.

134. Salem AEA, Barsoum BN, Saad GR, Izake EL (2002) Potentiometric determination of some 1,4-benzodiazepines in pharmaceutical preparations and biological samples. J Electroanal Chem 536: 1-9.
135. Amorim CG, Araújo AN, Montenegro MC, Silva VL (2008) Cyclodextrin-based potentiometric sensors for midazolam and diazepam. J Pharm Biomed Anal 48: 1064-1069.

136. Correia dos Santos MM, Famila V, Simões Gonçalves ML (2002) Copperpsychoactive drug complexes: a voltammetric approach to complexation by 1,4-benzodiazepines. Anal Biochem 303: 111-119.

137. Dos Santos MM, Famila V, Gonçalves ML (2002) Square-wave voltammetric techniques for determination of psychoactive 1,4-benzodiazepine drugs. Anal Bioanal Chem 374: 1074-1081.

138. Nunez-Vergara LJ, Bollo S, Olea-Azar C, Navarrete-Encina PA, Squella JA (1997) Cyclic voltammetric and EPR spectroscopic studies of benzodiazepines: loprazolam and flunitrazepam. J Electroanal Chem 436: 227-238.

139. Lozano-Chaves ME, Palacios-Santander JM, Cubillana-Aguilera LM, NaranjoRodriguez I, Hidalgo-Hidalgo-de-Cisneros JL (2006) Modified carbonpaste electrodes as sensors for the determination of 1,4-benzodiazepines: Application to the determination of diazepam and oxazepam in biological fluids. Sensors and Actuators B 115: 575-583.

140. Doménech-Carbó A, Martini M, de Carvalho LM, Viana C, Doménech-Carbó MT (2013) Standard additions-dilution method for absolute quantification in voltammetry of microparticles. Application for determining psychoactive 1,4-benzodiazepine and antidepressants drugs as adulterants in phytotherapeutic formulations. J Pharm Biomed Anal 80: 159-163.

141. de Carvalho LM, Correia D, Garcia SC, de Bairros AV, do Nascimento PC, et al. (2010) A new method for the simultaneous determination of 1,4-benzodiazepines and amfepramone as adulterants in phytotherapeutic formulations by voltammetry. Forensic Sci Int 202: 75-81.

142. Morris-Kukoski CL, Schaff JE, Reda LJ (2012) Benzodiazepines and metabolites from biological fluids by liquid chromatography electrospray tandem mass spectrometry. Methods Mol Biol 902: 43-52. 